\title{
$\beta$-Lactoglobulin Heptapeptide Reduces Oxidative Stress in Intestinal Epithelial Cells and Angiotensin II-Induced Vasoconstriction on Mouse Mesenteric Arteries by Induction of Nuclear Factor Erythroid 2-Related Factor 2 (Nrf2) Translocation
}

\author{
Giacomo Pepe $\left(\mathbb{D}\right.$, ${ }^{1}$ Manuela Giovanna Basilicata, ${ }^{1,2}$ Albino Carrizzo $\left(\mathbb{D},{ }^{3}\right.$ Simona Adesso, \\ Carmine Ostacolo, ${ }^{4}$ Marina Sala $\left(\mathbb{D},{ }^{1}\right.$ Eduardo Sommella, ${ }^{1}$ Marco Ruocco, ${ }^{1}$ \\ Stella Cascioferro, ${ }^{5}$ Mariateresa Ambrosio, ${ }^{3}$ Simona Pisanti, ${ }^{6}$ Veronica Di Sarno, ${ }^{1}$ \\ Alessia Bertamino, ${ }^{1}$ Stefania Marzocco ${ }^{(D},{ }^{1}$ Carmine Vecchione, ${ }^{3,6}$ and Pietro Campiglia $\mathbb{D}^{1,7}$ \\ ${ }^{1}$ Department of Pharmacy, University of Salerno, Fisciano, Italy \\ ${ }^{2}$ PhD Program in Drug Discovery and Development, University of Salerno, Fisciano, Italy \\ ${ }^{3}$ IRCCS Neuromed, Loc. Camerelle, Pozzilli, Italy \\ ${ }^{4}$ Department of Pharmacy, University of Naples Federico II, NA, Italy \\ ${ }^{5}$ Dipartimento di Scienze e Tecnologie Biologiche, Chimiche e Farmaceutiche (STEBICEF), University of Palermo, PA, Italy \\ ${ }^{6}$ Department of Medicine and Surgery, University of Salerno, Baronissi, Italy \\ ${ }^{7}$ European Biomedical Research Institute of Salerno, SA, Italy
}

Correspondence should be addressed to Pietro Campiglia; pcampigl@unisa.it

Received 5 December 2018; Revised 18 March 2019; Accepted 8 October 2019; Published 12 November 2019

Academic Editor: Maria U. Moreno

Copyright ( 2019 Giacomo Pepe et al. This is an open access article distributed under the Creative Commons Attribution License, which permits unrestricted use, distribution, and reproduction in any medium, provided the original work is properly cited.

\begin{abstract}
Peptides derived from buffalo dairy products possess multiple healthy properties that cannot be exerted as long as they are encrypted in parent proteins. To evaluate the biological activities of encrypted peptide sequences from buffalo ricotta cheese, we performed a simulated gastrointestinal (GI) digestion. Chemical and pharmacological characterization of the digest led to the identification of a novel peptide endowed with antioxidant and antihypertensive action. The GI digest was fractionated by Semiprep-HPLC, and fractions were tested against reactive oxygen species (ROS) release in an $\mathrm{H}_{2} \mathrm{O}_{2}$-treated intestinal epithelial cell line. UHPLC-PDA-MS/MS analysis revealed the presence of an abundant $\beta$-lactoglobulin peptide (BRP2) in the most active fraction. Pharmacological characterization of BRP2 highlighted its antioxidant activity, involving ROS reduction, nuclear factor erythroid 2-related factor 2 (Nrf2) activation, and cytoprotective enzyme expression. The bioavailability of BRP2 was evaluated in intestinal transport studies through a Caco-2 cell monolayer. Equal bidirectional transport and linear permeability indicate that BRP2 was absorbed mainly through passive diffusion. In addition to its local effects, the BRP2 administration on mouse mesenteric arteries was able to reduce the angiotensin II-induced vasoconstriction by the Nrf2 nuclear translocation, the reduction of the active form of Ras-related C3 botulinum toxin substrate 1 (Rac1), and the NADPH oxidase activity. These data further highlight the role of buffalo ricotta cheese-derived peptides against oxidative stress-related diseases and suggest their health-promoting potential.
\end{abstract}

\section{Introduction}

Food proteins are an important source of bioactive peptides. These are inactive, since encrypted in their parent sequences, but turn active when released by fermentation or ripening during food processing or by digestive enzymes during gastrointestinal transit $[1,2]$. Once released, the bioactive peptides are able to exert various physiological effects 
beneficial for human health [3]. In particular, bioactive peptides can either have local effects on the digestive tract or be absorbed through the intestine, playing a physiological role in tissues [4]. These peptides can exhibit various biological activities, such as antioxidant, antimicrobial, immunomodulatory, antithrombotic, and antihypertensive, depending on their amino acid sequence [5]. The size of active sequences may vary from two to twenty amino acid residues, and several peptides are known to reveal multifunctional properties since some regions in the primary structure of parent protein, considered "strategic zones," contain overlapping sequences [6].

The effect of natural antioxidant peptides on health by treatment and prevention of numerous diseases is of great interest nowadays due to their safety, small size, low toxicity, and high activity in addition to the negative consumer perception about synthetic drugs [7]. This is why food-derived antioxidant peptides have become an interesting target in food chemistry. Enhancement of the body's antioxidant defense mechanism through dietary supplementation would seem to be a practical approach to reduce the level of reactive oxygen species (ROS) [8-10].

ROS are produced in a well-regulated manner to help maintain homeostasis at the cellular level in the normal healthy tissues, play an important role as second messengers, and regulate cellular function by modulating signaling pathways [11]. An imbalance in the equilibration of prooxidant/antioxidant status determines oxidative stress, characterized by damage to cellular macromolecules such as DNA, proteins, and membrane lipids, by human aging, and by diseases, such as gastrointestinal (GI) and cardiovascular pathologies [12].

The GI tract is prone to ROS attack as it is accessed by the outside environment with dietary factors that, together with resident immune cells and intestinal flora, are potential sources of ROS.

ROS have been linked with various inflammatory GI disorders such gastroesophageal reflux disease, gastritis, enteritis, colitis, and associated cancers as well as pancreatitis and liver cirrhosis [13]. Several studies demonstrate that oxidative stress also plays an important role in the pathogenesis and development of cardiovascular diseases, including hypertension, dyslipidemia, diabetes mellitus, atherosclerosis, myocardial infraction, angina pectoris, and heart failure [14]. In fact, oxidative stress is considered to be the main cause of endothelial dysfunction leading to cardiovascular complications, mostly through the reduction of nitric oxide (NO) bioavailability, which is one of the most important mediators of the physiological properties of endothelial cells. The increased production of ROS and decreased NO bioavailability promote endothelial dysfunction, leading to remodeling, platelet aggregation, loss of vasodilation, inflammation, and smooth muscle cell growth [15]. An imbalance between NO and ROS has been observed in patients with hypertension [16].

In order to prevent and counteract some GI pathologies and cardiovascular diseases, the employment of natural antioxidant molecules is crucial. Dairy products and their fractions can be considered carriers for the delivery of antioxidant peptides. We recently evidenced the antioxidant properties of buffalo milk dairy products and in particular buffalo ricotta cheese $[17,18]$.
In addition, several studies showed the antihypertensive effect of whey protein as renin-angiotensin-converting enzyme inhibitors, direct stimulators of endothelial NO, opioid receptor agonists, or direct inhibitors of endothelin1 production, but no studies were described concerning the hypotensive activity of buffalo whey protein-derived peptides [19-22].

In this regard, the aim of the present work was to investigate the release, the intestinal absorption, and the biological activities of potential antioxidant peptides after simulated oral intake of buffalo ricotta cheese. After in vitro gastrointestinal digestion, the sample was separated into two fractions that were challenged for its antioxidant properties. The peptidomic workflow led to the identification of an abundant $\beta$-lactoglobulin peptide in the most active fraction. The effect of this peptide on oxidative stress induced by $\mathrm{H}_{2} \mathrm{O}_{2}$ in the intestinal epithelial cells (IEC-6) and by angiotensin II in mouse mesenteric arteries was evaluated, together with its bioavailability.

\section{Materials and Methods}

2.1. Preparation and Fractionation of Buffalo Ricotta Gastrointestinal Digest by Semiprep-RP-HPLC. The simulated gastrointestinal digestion of buffalo ricotta cheese was performed according to Pepe et al. [23]. Briefly, the lyophilized sample was incubated with pepsin at $37^{\circ} \mathrm{C}$ for $2 \mathrm{~h}$ to $\mathrm{pH}=2$, and the reaction was stopped by heating the solution at $95^{\circ} \mathrm{C}$ for $15 \mathrm{~min}$. Then, the gastric digest was incubated with pancreatin, chymotrypsin, and bile salts at $37^{\circ} \mathrm{C}$ for $2 \mathrm{~h}$ to $\mathrm{pH} 7.5$, and the reaction was stopped bringing the solution to $\mathrm{pH} 2$.

The peptides released after gastrointestinal digestion of buffalo ricotta cheese were fractionated by semipreparative reversed-phase liquid chromatography. For the separation, a Shimadzu Semiprep-HPLC was employed consisting of two LC-20 AP pumps, a SIL-20 AP autosampler, a fraction collector FRC-10 A, a UV detector SPD-20 A equipped with a preparative cell, and a system controller CBM-20 A.

The separation was carried out on a Kinetex ${ }^{\mathrm{TM}} \mathrm{C} 18$ column $(150 \times 21.2 \mathrm{~mm} \times 5 \mu \mathrm{m} \quad(100 \AA))$, and flow rate $\left(20 \mathrm{~mL} \mathrm{~min}^{-1}\right)$, injection volume $\left(5 \mathrm{~mL}\left(2 \mathrm{mg} \mathrm{mL}^{-1}\right)\right)$, detection UV (214 and $220 \mathrm{~nm}$ ), and the collection were based on UV-triggering signal. The optimal mobile phase consisted of (A) $\mathrm{H}_{2} \mathrm{O}$ and (B) ACN both acidified by trifluoroacetic acid $0.1 \%(v / v)$. Analysis was performed in gradient elution as follows: $0.01-5.00 \mathrm{~min}$, isocratic to $1 \% \mathrm{~B} ; 5-40.00 \mathrm{~min}, 1-$ $35 \% \mathrm{~B}$; $40-43.00 \mathrm{~min}, 35-95 \% \mathrm{~B}$; and $43-46.00 \mathrm{~min}$, isocratic to $95 \% \mathrm{~B}$, and then five minutes for column reequilibration. The fractions were collected on the basis of their elution times and thus hydrophobicity. In detail, the fractionation of peptide digesta led to the collection of two different aliquots: fraction I (BRF1), from $10.00 \mathrm{~min}$ to $20.00 \mathrm{~min}$, and fraction II (BRF2), from 20.00 to $30.00 \mathrm{~min}$.

2.2. Peptide Identification in the BRF2. Analyses of the bioactive peptides contained in the BRF2 were performed on a Shimadzu Nexera UHPLC system coupled online to an LCMS-IT-TOF mass spectrometer through an ESI source 
(Shimadzu, Kyoto, Japan). Separation of BRF2 was carried out on an Aeris ${ }^{\mathrm{TM}}$ Peptide XB-C18 column $(100 \times 2.1 \mathrm{~mm} \times 1.7 \mu \mathrm{m}) \quad($ Phenomenex, Bologna, Italy) The flow rate and the column oven temperature were set to $0.5 \mathrm{~mL} \mathrm{~min}^{-1}$ and $60^{\circ} \mathrm{C}$, respectively. The chromatograms were monitored at 214 and $220 \mathrm{~nm}$. The mobile phase for the analysis of BRF2 consisted of $0.1 \%(v / v) \mathrm{HCOOH} / \mathrm{H}_{2} \mathrm{O}$ (A) and $0.1 \%(v / v) \mathrm{HCOOH} / \mathrm{ACN}(\mathrm{B})$. Analysis was performed in gradient elution as follows: $0.01-45.0 \mathrm{~min}, 0-30 \%$ $\mathrm{B}$; $45-47.00 \mathrm{~min}, 30-95 \% \mathrm{~B}$; and $47-49.00 \mathrm{~min}$, isocratic to $95 \% \mathrm{~B}$, and then five minutes for column reequilibration.

MS detection was operated in $\mathrm{ESI}^{+}$mode, and MS/MS experiments were conducted in data-dependent acquisition; precursor ions were acquired in the range $300-2000 \mathrm{~m} / \mathrm{z}$.

A free trial of PEAKS 7.5 software (Bioinformatics Solutions Inc., Waterloo, Canada) was employed for sequence determination. A search was performed using a database search tool, by searching against the SwissProt/UniProt database (database Bubalus bubalis release 2017).

2.3. Synthesis and Quantification of Buffalo Ricotta Peptide 2 (BRP2). Synthesis of the analogue peptide was performed according to the solid phase approach using standard Fmoc methodology, with a Biotage Initiator+Alstra (Uppsala, Sweden) automated microwave synthesizer (for detailed conditions, see Supporting Information Appendix S1).

The quantification of BRP2 in buffalo ricotta digesta and BRF2 was performed on a Nexera UHPLC system coupled online to an LCMS-8050 mass spectrometer (Shimadzu, Kyoto, Japan), equipped with an ESI source operated in positive mode. MS/MS analysis was conducted in selected reaction monitoring (SRM), employing the synthetic peptide as an external standard. Stock solution was prepared in water, the calibration curve was obtained in a concentration range of $0.1-125 \mu \mathrm{g} \mathrm{L}^{-1}$ with eight concentration levels, and triplicate injection of each level was run. Peak areas of BRP2 were plotted against the corresponding concentrations. Linear regression was used to generate the calibration curve $(y=0.0004 x-1.5321)$ with $R^{2}$ values being $\geq 0.9998$ (see Supporting Information Appendix S2).

2.4. IEC-6 Cells: Culture, Treatment, and Viability Assay. The IEC-6 cell line (CRL-1592), derived from normal rat intestinal crypt cells, was purchased from the American Type Culture Collection (ATCC, Rockville, MD, USA).

These cells were cultured by using Dulbecco's modified Eagle's medium (DMEM) (4g/L glucose), supplemented with $10 \%(v / v)$ heat-inactivated foetal bovine serum, $1.5 \mathrm{~g} / \mathrm{L}$ $\mathrm{NaHCO}_{3}, 2 \mathrm{mM} \mathrm{L}$-glutamine, and 0.1 unit $\mathrm{mL}^{-1}$ bovine insulin. Cells were used, for the experiments, between the $17^{\text {th }}$ and $21^{\text {st }}$ passages.

The IEC-6 cells $\left(2 \times 10^{4}\right)$ were plated into 96-multiwell plates and allowed to adhere. After $24 \mathrm{~h}$, cells were exposed to BRF1 and BRF2 (50-1.25 $\left.\mu \mathrm{g} \mathrm{mL}^{-1}\right)$ and BRP2 (100-1 $\left.\mu \mathrm{M}\right)$, for $24 \mathrm{~h}$. Cell viability was then assessed using the MTT assay, as previously reported [24].

2.4.1. Measurement of Intracellular ROS Release. ROS levels were evaluated by means of the probe $2^{\prime}, 7^{\prime}$-dichlorofluor- escin-diacetate $\left(\mathrm{H}_{2} \mathrm{DCF}-\mathrm{DA}\right)$ [25]. For this experiment, IEC-6 cells were plated into 24 -well plates $\left(8 \times 10^{4}\right.$ cells /well). After adhesion time of $24 \mathrm{~h}$, cells were then treated with BRF1 and BRF2 (50-1.25 $\left.\mu \mathrm{g} \mathrm{mL}^{-1}\right)$ and with BRP2 (100-1 $\mu \mathrm{M})$, for $1 \mathrm{~h}$, either alone or in the presence of $\mathrm{H}_{2} \mathrm{O}_{2}$ $(1 \mathrm{mM})$ for further $1 \mathrm{~h}$.

IEC-6 cells were then collected, and a PBS buffer was used in order to wash them. Subsequently, cells were incubated in PBS containing $\mathrm{H}_{2}$ DCF-DA $(10 \mu \mathrm{M})$, for $15 \mathrm{~min}$ at $37^{\circ} \mathrm{C}$. A fluorescence-activated cell sorter (FACSscan; Becton Dickinson, Franklin Lakes, NJ, USA) was used for the purpose of measuring cell fluorescence, and CellQuest software (Becton Dickinson, Milan, Italy) was employed in order to analyze it.

2.4.2. Immunofluorescence Analysis for Nuclear Factor-Like 2 Activation. IEC-6 cells $\left(2 \times 10^{5}\right.$ cells/well $)$ were seeded on coverslips in a 12-well plate and treated with BRP2 at concentration of $50 \mu \mathrm{M}$ for $1 \mathrm{~h}$, both alone and in the presence of $\mathrm{H}_{2} \mathrm{O}_{2}(1 \mathrm{mM})$ for further $1 \mathrm{~h}$ in order to evaluate nuclear factor- (erythroid-derived 2) like 2 (Nrf2) activation. After the cellular treatment, 4\% paraformaldehyde in PBS was used to fix the cells. Then, IEC- 6 cells were permeabilized with $0.1 \%$ saponin in PBS. After the blocking made with BSA and PBS, cells were incubated with a rabbit anti-Nrf2 antibody (Santa Cruz Biotechnology, Dallas, TX, USA) for $1 \mathrm{~h}$ at $37^{\circ} \mathrm{C}$. The slides were then washed three times with PBS. After that, a fluorescein-conjugated secondary antibody (FITC) was added for further $1 \mathrm{~h} .4^{\prime}, 6$-diamidine- $2^{\prime}$-phenylindole dihydrochloride (DAPI) was used for the counterstaining of nuclei. At the end, coverslips were mounted in mounting medium. Fluorescent images were taken under the laser confocal microscope (Leica TCS SP5, Leica, Wetzlar, Germany) as previously reported [26].

2.4.3. Measurement of Heme Oxygenase 1 (HO-1), NAD(P)H Quinone Dehydrogenase 1 (NQO1), and Superoxide Dismutase (SOD) Expression. IEC-6 cells were plated into 96-well plates $\left(1 \times 10^{4}\right.$ cells/well $)$ and allowed to adhere. After $24 \mathrm{~h}$, cells were treated with BRP2 $(100-1 \mu \mathrm{M})$ for $1 \mathrm{~h}$, either alone or in the presence of $\mathrm{H}_{2} \mathrm{O}_{2}(1 \mathrm{mM})$ for further $1 \mathrm{~h}$. After cellular treatment, IEC- 6 cells were collected, washed with PBS, and incubated in fixing solution for $20 \mathrm{~min}$ and then in Fix Perm Solution for further $30 \mathrm{~min}$. Anti-heme oxygenase 1 (Santa Cruz Biotechnology, Dallas, TX, USA), anti-NAD $(\mathrm{P}) \mathrm{H}$ quinone dehydrogenase 1 (Santa Cruz Biotechnology, Dallas, TX, USA), or anti-superoxide dismutase (Santa Cruz Biotechnology, Dallas, TX, USA) antibodies were then added. The cells were then treated with the secondary antibody. A fluorescence-activated cell sorter (FACSscan; Becton Dickinson, Franklin Lakes, NJ, USA) was used for the purpose of measuring cell fluorescence, and CellQuest software (Becton Dickinson, Milan, Italy) was employed in order to analyze it.

\subsection{In Vitro Intestinal Transepithelial Transport Studies}

2.5.1. Caco-2 Cell Monolayer Permeation Experiments. The colorectal adenocarcinoma (Caco-2) cell line was purchased from ATCC (Rockville, MD, USA). Cells were maintained 
in high-glucose DMEM (4.5 g/L) supplemented with $2 \mathrm{mM}$ L-glutamine and $10 \%(v / v)$ heat-inactivated foetal bovine serum. Cells were cultured at $37^{\circ} \mathrm{C}$ in a humidified $5 \% \mathrm{CO}_{2}$ atmosphere. To induce enterocytic Caco- 2 differentiation, cells were seeded in a 12-well multiwell in transwell inserts (PET membrane, $0.4 \mu \mathrm{m}$ pore size, $1.12 \mathrm{~cm}^{2}$ surface area) at $2.6 \times 10^{5}$ cells $/ \mathrm{cm}^{2}$ and maintained for 21 days in complete medium. The medium was changed every second day. By 21 days, the monolayers become completely differentiated.

The integrity of the monolayers was evaluated by measurement of the transepithelial electrical resistance (TEER) using an EVOM2 epithelial voltohmmeter (World Precision Instruments, Sarasota, FL, USA). Only monolayers showing TEER higher than $300 \Omega \times \mathrm{cm}^{2}$ were then used for transport experiments. The integrity of the monolayers was checked before, during, and after the experiment. The filters were washed for $15-20 \mathrm{~min}$ at $37^{\circ} \mathrm{C}$ adding prewarmed Hank's balanced salt solution buffered with $25 \mathrm{mM}$ HEPES and $\mathrm{NaHCO}_{3}(0.35 \mathrm{~g} / \mathrm{L})$ at $\mathrm{pH} 7.4$ to the apical $(0.4 \mathrm{~mL})$ and to the basolateral $(1.2 \mathrm{~mL})$ transwell compartments, as previously described [27]. For transport experiments, donor solution containing BRP2 peptide at the desired concentration $(100-1 \mu \mathrm{M})$ was added to the apical compartment for the apical to basolateral (absorptive) direction. Samples from the receiving compartment were collected at different time points up to $120 \mathrm{~min}(15,30,60,90$, and $120 \mathrm{~min})$. Samples from the donor compartment were collected at time 0 and at the end of the experiment $(120 \mathrm{~min})$ for the calculation of the mass balance.

Samples were stored at $-20^{\circ} \mathrm{C}$ until UHPLC-MS/MS analyses to measure the concentration of BRP2 in both compartments (for detailed conditions, see Supporting Information Appendix S2).

The apparent permeability coefficient $\left(P_{\text {app }}\right)$ was calculated as described according to

$$
P_{\text {app }}=\frac{d M_{\mathrm{R}^{(t)}}}{d t} \times \frac{1}{A \times C_{\mathrm{D} 0}},
$$

where $M_{\mathrm{R}}$ is the amount of substance in the receiver chamber, $A\left(\mathrm{~cm}^{2}\right)$ is the surface area of the barrier, and $C_{\mathrm{D} 0}$ $(\mu \mathrm{M})$ is the initial donor concentration. The reduction in donor concentration was also taken after every sampling (see Supporting Information Appendix S3) [28].

2.5.2. Immunofluorescence Analysis on Caco-2 Cell Monolayers. The transwell membranes from TEER experiments were washed with PBS and fixed with $4 \%$ paraformaldehyde (PFA) for $15 \mathrm{~min}$. Membranes were then washed in PBS and blocked with blocking solution $(0.1 \%$ Triton, $1 \%$ BSA, $0.02 \%$ sodium azide, and $50 \mathrm{mM}$ ammonium chloride) for $20 \mathrm{~min}$ at room temperature in the dark. Afterwards, they were incubated with an anti-zonulin 1 antibody (\#402200, Invitrogen, Thermo Fisher Scientific, Waltham, MA, USA) at the final concentration of $2 \mu \mathrm{g} \mathrm{mL}^{-1}$ at room temperature for 2 hours. Immunofluorescence staining was obtained by incubating the membranes for $90 \mathrm{~min}$ with Alexa Fluor 488 donkey anti-rabbit IgG (\#A31573) at the final concentration of $4 \mu \mathrm{g} \mathrm{mL}^{-1}$ (Invitrogen). The nuclei were counterstained with DAPI $(1: 2000)$. Membranes were cut down with an operating knife blade along the margin of the chamber and were mounted on slides using VectaMount solution (AQ Vector Laboratories, Burlingame, CA, USA). Slides were examined under a Nikon fluorescence inverted microscope (Nikon Instruments Europe, Firenze, Italy) and then analyzed through ImageJ software as previously described [29].

2.6. Vascular Reactivity Studies. Second-order branches of the mesenteric arterial tree (internal diameter between 150 and $250 \mu \mathrm{m}$ ) were dissected and mounted on a wire myograph as previously described [30]. Briefly, vessels were equilibrated for $60 \mathrm{~min}$ at $45 \mathrm{mmHg}$ intraluminal pressure in warmed oxygenated (95:5\%, air: $\left.\mathrm{CO}_{2}\right)$ Krebs solution ( $\mathrm{pH}$ 7.4) containing the following $\left(\mathrm{mmol} \mathrm{L}^{-1}\right): 120 \mathrm{NaCl}, 25$ $\mathrm{NaHCO}_{3}, 4.7 \mathrm{KCl}, 1.18 \mathrm{KH}_{2} \mathrm{PO}_{4}, 1.18 \mathrm{MgSO}_{4}, 2.5 \mathrm{CaCl}_{2}$, 0.026 EDTA, and 5.5 glucose. Media and lumen diameters were measured with a computer-based video imaging system (Danish Myo Technology). Endothelium-dependent and endothelium-independent relaxation was assessed by measuring the dilatory responses to cumulative doses of acetylcholine (Ach, $10^{-9}$ to $10^{-5} \mathrm{~mol} \mathrm{~L}^{-1}$ ) or nitroglycerine (Nitro, $10^{-9}$ to $10^{-5} \mathrm{~mol} \mathrm{~L}^{-1}$ ), respectively, in vessels precontracted with phenylephrine $\left(10^{-9}\right.$ to $\left.10^{-5} \mathrm{~mol} \mathrm{~L}^{-1}\right)$. After evaluation of basal vascular function, we have tested the effect of peptide on angiotensin II-induced vasoconstriction (Ang II, $10^{-9}$ to $\left.10^{-5} \mathrm{~mol} \mathrm{~L}^{-1}\right)$, preincubating the vessels with different dosages of BRP2 (100-1 $\left.\mu \mathrm{mol} \mathrm{L}^{-1}\right)$.

2.6.1. Dihydroethidium (DHE) Staining. DHE was used to evaluate the levels of oxidative stress in mouse mesenteric arteries as previously described [31]. Briefly, vessels were stained with $5 \mathrm{~mol} \mathrm{~L}^{-1} \mathrm{DHE}$ for $20 \mathrm{~min}$, then mounted and observed under a fluorescence microscope (Zeiss, Oberkochen, Germany). Images were acquired by a digital camera system.

2.6.2. NADPH Oxidase Activity Measurement. NADPH oxidase (NOX) activity in a pool of mesenteric arteries was measured in untreated cells and cells treated with angiotensin II and preincubated with BRP2 plus Ang II as previously described [31]. In another experimental set, we measure NADPH oxidase activity in IEC-6 cells following the same protocol but using $150 \mu \mathrm{g}$ of protein extract. Vessels were placed in a chilled modified Krebs/HEPES buffer. Periadventitial tissue was carefully removed, and the vessels were repeatedly washed to remove adherent blood cells. A $10 \%$ vessel homogenate was prepared in $50 \mathrm{mmol} \mathrm{L}^{-1}$ phosphate buffer containing $0.01 \mathrm{mmol} \mathrm{L}^{-1}$ EDTA. The homogenate was then subjected to low-speed centrifugation (1000 g) for $10 \mathrm{~min}$ to remove unbroken cells and debris. $20 \mu \mathrm{L}$ was added to glass scintillation vials containing $5 \mu \mathrm{mol} \mathrm{L}{ }^{-1}$ lucigenin in $1 \mathrm{~mL}$ phosphate buffer. The chemiluminescence that occurred over the ensuing $5 \mathrm{~min}$ in response to the addition of $100 \mu \mathrm{mol} \mathrm{L}^{-1} \mathrm{NADPH}$ was recorded (Beckman LS6500 Multipurpose Scintillation Counter; Beckman Coulter, Fullerton, CA). In preliminary experiments, homogenates alone without the addition of NADPH gave only minimal 
signals. Furthermore, NADPH did not evoke lucigenin chemiluminescence in the absence of homogenate.

2.6.3. Immunoblotting and Nuclear/Cytoplasmic Fractionation. Immunoblots were performed as previously described [32]. Briefly, $30 \mu \mathrm{g}$ tissue extract for each sample was separated by SDS-PAGE and transferred onto a nitrocellulose membrane. Blocked membranes were incubated with primary antibodies in TBS-Tween and 5\% milk overnight. Blocked membranes were then incubated with anti-MnSOD $(1: 1500)$ and anti- $\beta$-actin $(1: 1000)$.

Nuclear and cytoplasmic fractions, obtained as previously described [32], were separated by SDS-PAGE and transferred onto nitrocellulose membranes [32]. Blocked membranes were incubated with anti-Nrf2 $(1: 2000)$, antiGAPDH (glyceraldehyde 3-phosphate dehydrogenase, $1: 3000$ ), and anti-HDAC2 (histone deacetylase 2, 1:2000) overnight and then detected using an appropriate horseradish peroxidase-coupled secondary antibody (Millipore, Milan, Italy) and visualized with enhanced chemiluminescence. The purity of nuclear and cytoplasmic fractions was confirmed using anti-HDAC2 and anti-GAPDH, respectively. Immunoblotting data were analyzed using ImageJ software (developed by Wayne Rasband, National Institutes of Health, USA) to determine OD of the bands. The OD reading was normalized to account for variations in loading.

2.6.4. Ras-Related C3 Botulinum Toxin Substrate 1- (Rac1-) GTP Pull-Down Experiments. Mesenteric arteries were lysed in a buffer containing NP-40 equipped with kit STA-401-1 (Cell Biolabs Inc., San Diego, CA). The p21-binding domain of p21-activated protein kinase bound to agarose beads was added, and active Rac1, binding to PAK1, was separated by repetitive centrifugation and washing. Then, the specimens were boiled in Laemmli buffer and subjected to SDS-PAGE, and Rac1 was quantified by immunoblot analysis. In detail, Rac1-GTP was detected with the monoclonal antibody antiRac1-GTP c (1:800; STA-401-1, Cell Biolabs Inc.) and total Rac1 with monoclonal anti-Rac1 (1:1000; Abcam). The amount of Rac1-GTP was normalized to the total amount of Racl in tissue lysates for the comparison of Racl activity (GTP-bound Rac1) among different samples.

2.7. Data Analysis. Data were reported as mean \pm standard error mean values, of at least three independent experiments, each in triplicate. In order to analyze the effects of our treatments on increasing doses of acetylcholine, we performed a 2-way repeated measures ANOVA with the Bonferroni post hoc test for multiple comparisons. Statistical analysis was performed by analysis of the variance test, and multiple comparisons were made by the Bonferroni test. A $p$ value less than 0.05 was considered significant.

\section{Results}

3.1. Antioxidant Effect of BRP2 on ROS Release in IEC-6 Cells Treated with $\mathrm{H}_{2} \mathrm{O}_{2}$. With the aim of investigating the potential of buffalo ricotta cheese against oxidative stress induced by $\mathrm{H}_{2} \mathrm{O}_{2}$ in IEC- 6 cells, the intracellular ROS production was measured. The GI digest of buffalo ricotta cheese was separated into two different fractions BRF1 and BRF2 by Semiprep-RPLC (Figure 1(a)).

No cytotoxic effect was observed when IEC-6 cells were treated with BRF1 and BRF2 fractions (data not shown). On the other hand, both tested fractions significantly reduced ROS release in a concentration-dependent manner $(p<0.05$ vs. $\mathrm{H}_{2} \mathrm{O}_{2}$; Figure $1(\mathrm{~b})$ ), with $\mathrm{BRF} 2$ fraction showing higher efficacy $(p<0.01$ vs. BRF1; Figure 1(b)).

Thus, we focused on the identification of most abundant peptides of this fraction by UHPLC-PDA-MS/MS analysis. An intense peak in BRF2 was selected and identified as BRP2 (Figure 2(a)), namely, Ser-Phe-Asn-Pro-Thr-Gln-Leu ( $\beta$-LG, f168-174, and SFNPTQL, Figure 2(b)). The relative amount of the peptide was calculated by MS/MS in $1 \mathrm{mg}$ of BR digest and BRF2 $(14.73 \pm 0.38 \% \mu \mathrm{M}$ and $33.48 \pm 0.56 \mu$ $M$, respectively).

To investigate its biological properties, the peptide was synthesized by an Fmoc solid-phase approach (see Supporting Information Figure S1). Finally, the antioxidant potential of BRP2 was tested in IEC- 6 cells treated with $\mathrm{H}_{2} \mathrm{O}_{2}$. Our results showed that $\mathrm{BRP} 2$ caused, at all tested concentrations (100-1 $\mu \mathrm{M})$, a significant decrement of ROS release induced by $\mathrm{H}_{2} \mathrm{O}_{2}\left(1 \mathrm{mM} ; p<0.01\right.$ vs. $\mathrm{H}_{2} \mathrm{O}_{2}$, Figure 2(c)), thus exerting a cytoprotective effect against induced oxidative stress.

3.2. Evaluation of BRP2 Bioavailability. To assess BRP2 bioavailability, its transmembrane permeability was evaluated through Caco-2 fully differentiated cell monolayers [28]. As shown in Figure S2 (see Supporting Information), the transport amounts of BRP2 increased approximately linearly, in a time- (0-120 min) and concentrationdependent $(1-100 \mu \mathrm{M})$ manner.

BRP2 showed moderate transport due to $P_{\text {app }}$ values, ranging from 0.20 to $0.53 \times 10^{-6} \mathrm{~cm} / \mathrm{s}$ (see Supporting Information Table S1). Finally, the $P_{\text {app }}$ of BRP2 in the apical to basolateral direction (A-B), as well as that in the basolateral to apical direction (B-A), was compared to explore the possible transport mechanism. In particular, the efflux ratio, defined as the quotient of the secretory permeability and the absorptive permeability (B-A/A-B), was less than 1 suggesting that passive diffusion could be the main intestinal transport mechanism of BRP2 [33]. Moreover, in order to evaluate the effects of BRP2 on Caco-2 monolayer integrity and cell vitality, we performed immunofluorescence analysis on transwell inserts at the end of transport studies. As shown in Figure S3 (see Supporting Information), Caco-2 cell monolayer integrity was preserved upon BRP2 treatment at all the concentrations tested as confirmed by tight junction protein zonulin-1 expression (green) and cell vitality.

3.3. BRP2 Reduces Angiotensin II-Induced Vasoconstriction and Oxidative Stress in the Mouse Mesenteric Artery. In order to investigate the antioxidant capability of BRP2 also in ex vivo model able to reproduce the cardiovascular condition of the vascular system, we performed experiments on the mouse mesenteric artery that is considered the prototype of resistance vessels involved in the modulation of systemic 


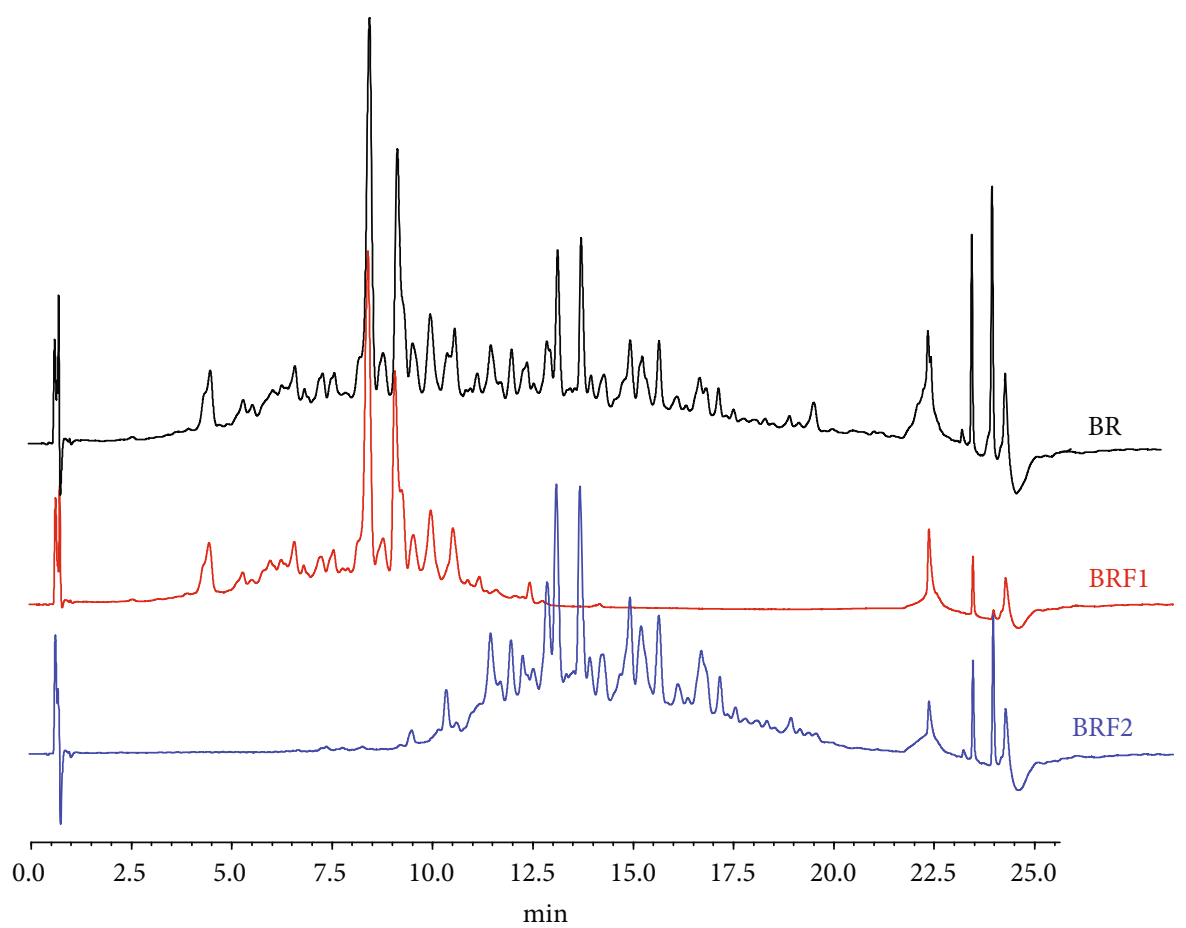

(a)

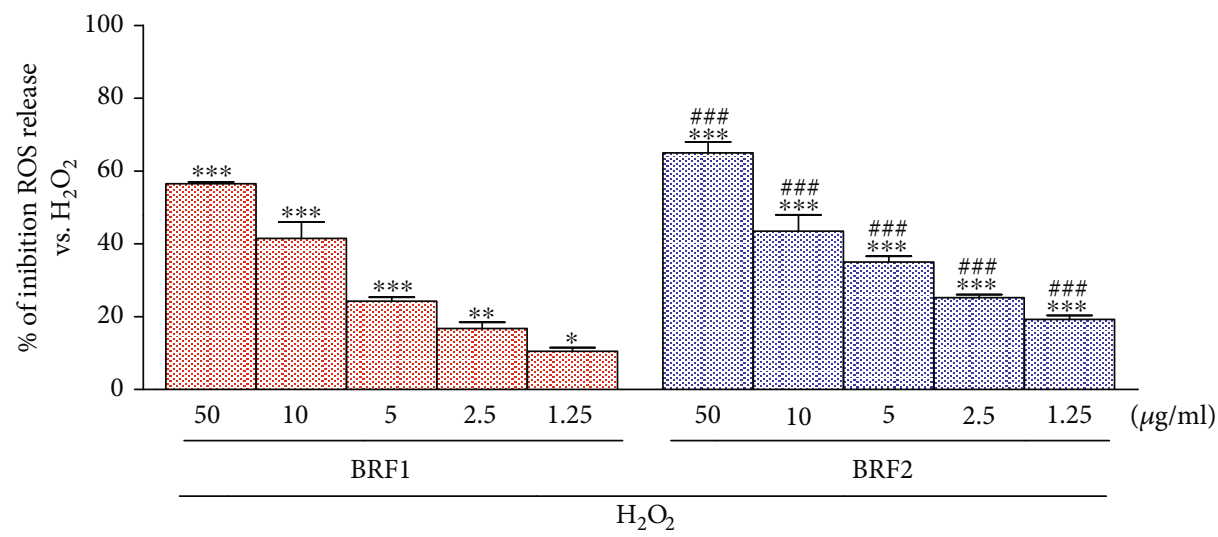

(b)

FIGURE 1: (a) Chromatographic profiles ( $\lambda: 214 \mathrm{~nm}$ ) of the gastrointestinal digest of BR (black line), BRF1 (red line), and BRF2 (blue line). (b) Effect of BRF1 and BRF2 fractions on ROS formation, in IEC- 6 cells, evaluated by $\mathrm{H}_{2}$ DCF-DA. Values, mean \pm s.e.m., are expressed as $\%$ of

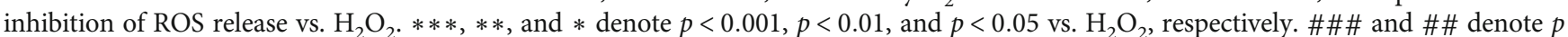
$<0.001$ and $p<0.01$ vs. $\mathrm{BRF} 1+\mathrm{H}_{2} \mathrm{O}_{2}$, respectively.

hemodynamic parameter. Interestingly, the preincubation of mesenteric arteries with increasing doses of BRP2 showed a progressive dose-dependent reduction of Ang II-induced vasoconstriction (Figure 3(a)), with maximal effects at $100 \mu \mathrm{M}$, with a reduction of the Ang II-vasoconstrictive response of about $92.0 \pm 4.0 \%$ (Figure 3(b)). This functional effect drove us to explore its action on the oxidative stress status, since oxygen-derived free radicals are selectively involved in the vascular response to Ang II. By DHE staining, we showed that BRP2 specifically reduces the Ang II-induced ROS production (Figure 3(c)). To support this effect, the measurement of NOX activity revealed that BRP2 is capable of markedly attenuating the lucigenin signal in a dosedependent manner (Figure 3(d)).
3.4. Antioxidant and Hypotensive Effects of BRP2. The endogenous antioxidant system mainly consists of intracellular enzymatic antioxidants that are responsible for redox homeostasis balance. Nrf2 is an intracellular transcription factor that regulates the expression of several genes to activate antioxidative enzymes and detoxifying factors [34]. For these reasons, in order to give an insight into the molecular mechanisms underlying the antioxidant effects of BRP2, its influence on this specific antioxidant pathway was studied.

As shown in Figure 4(a), nuclear Nrf2 levels are increased in IEC-6 cells treated with BRP2 $(50 \mu \mathrm{M})+\mathrm{H}_{2} \mathrm{O}_{2}$ ( $1 \mathrm{mM})$, with respect to $\mathrm{H}_{2} \mathrm{O}_{2}$ alone. It is known that $\mathrm{Nrf} 2$ activation leads to the expression of cytoprotective enzymes. In our experimental model, the effect of BRP2 


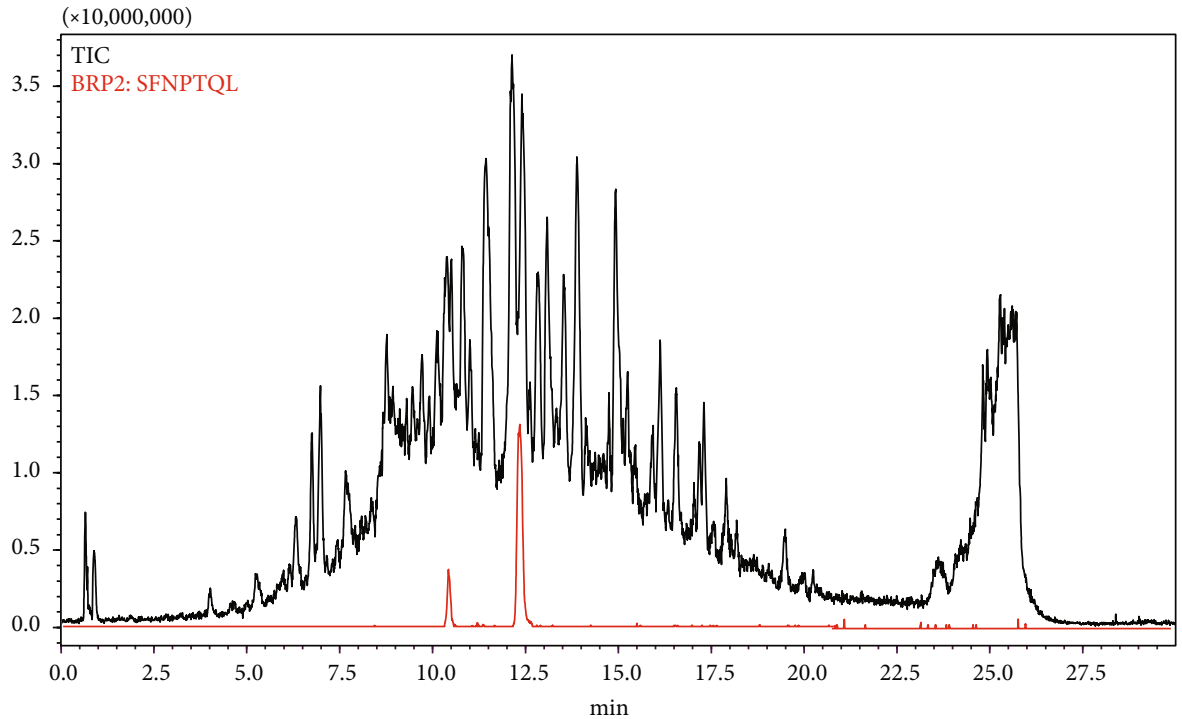

(a)

Intensity (\%) SF NPTQL
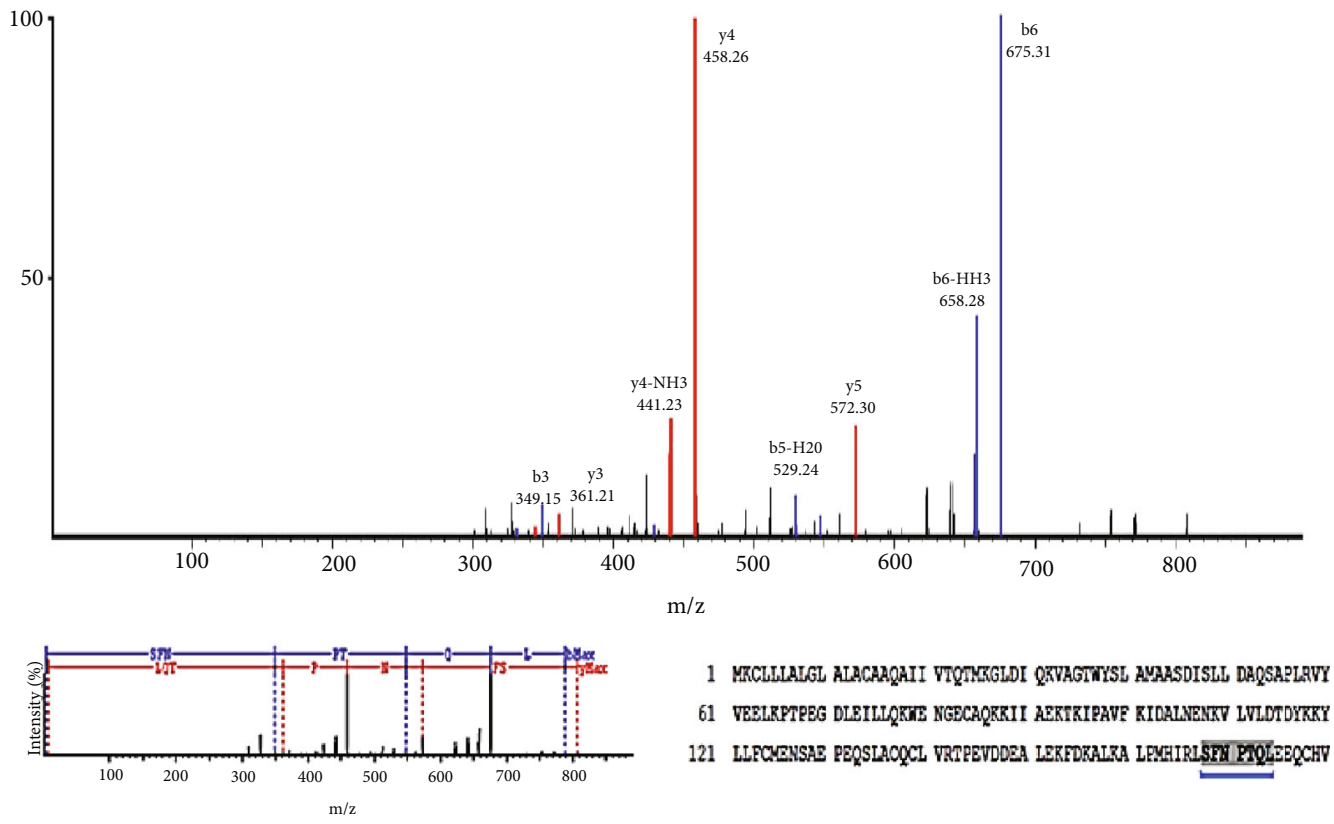

(b)

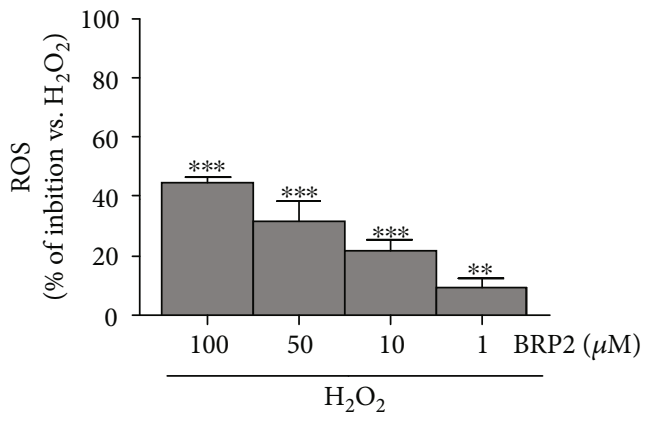

(c)

FIGURE 2: (a) Total ion chromatogram of BRF2 and (b) MS/MS fragmentation pattern of identified BRP2 (SFNPTQL) in BRF2 fraction. (c) Effect of BRP2 on ROS formation in $\mathrm{H}_{2} \mathrm{O}_{2}$-treated IEC- 6 cells. Values, mean \pm s.e.m., are expressed as $\%$ of inhibition of $\mathrm{ROS}$ vs. $\mathrm{H}_{2} \mathrm{O}_{2}$. $* * *$ and $* *$ denote $p<0.001$ and $p<0.01$ vs. $\mathrm{H}_{2} \mathrm{O}_{2}$. 


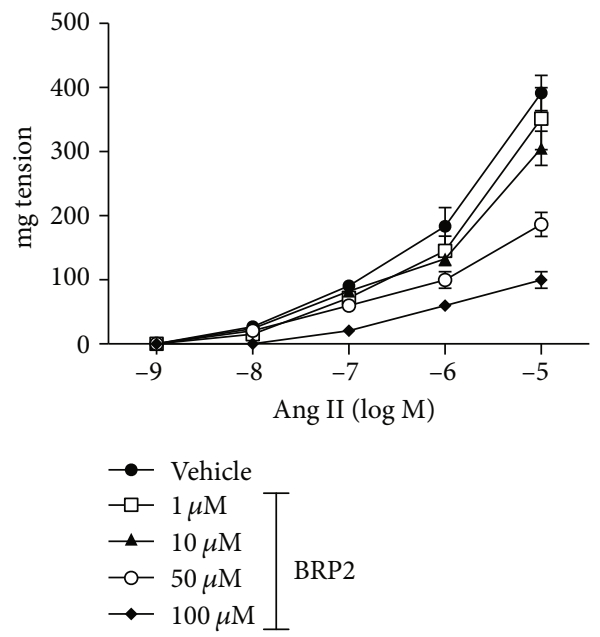

(a)

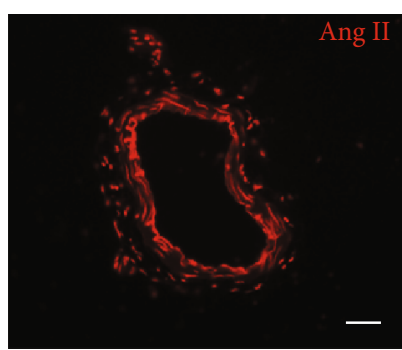

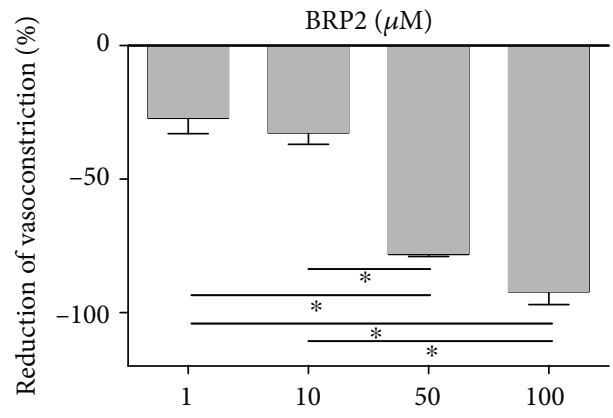

(b)
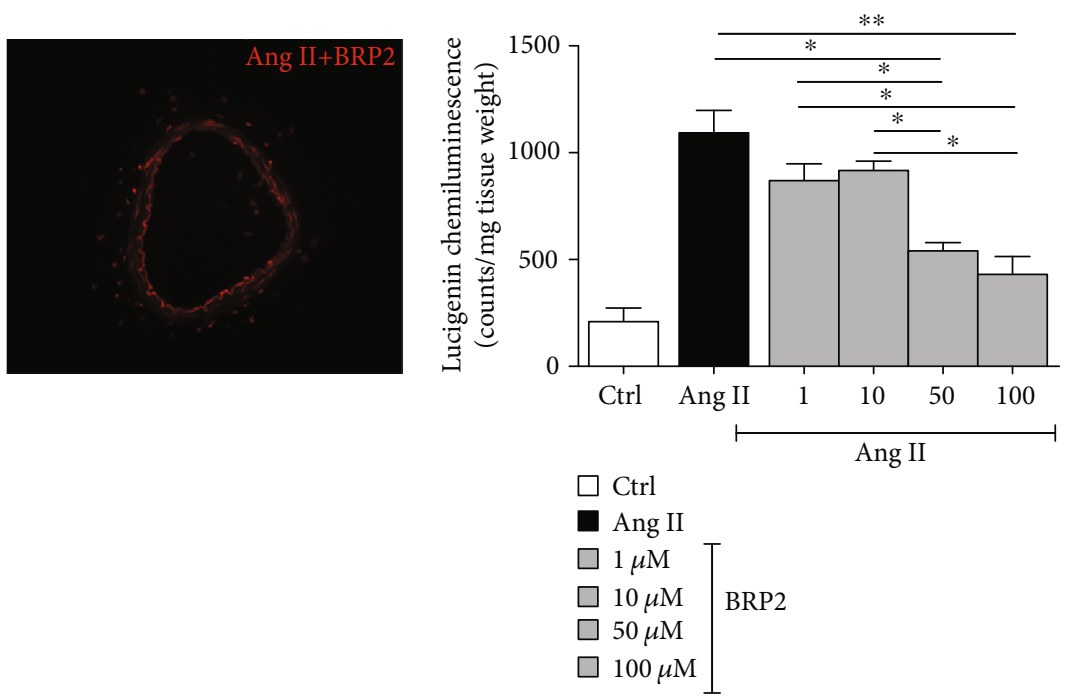

(c)

(d)

FIGURE 3: (a) Vascular responses to increasing doses of angiotensin II $\left(10^{-9}\right.$ to $\left.10^{-5}\right)$ of mouse mesenteric arteries preincubated with increasing doses of BRP2 $(1,10,50$, and $100 \mu \mathrm{M})$. (b) Bar graph of the last time point of dose-response curve to angiotensin II (10 $\left.{ }^{-5} \mathrm{M}\right)$. (c) In situ detection of superoxide generation with DHE staining in segments of mesenteric arteries treated with Ang II (10 $\left.{ }^{-5} \mathrm{M}\right)$ alone or plus BRP2 $(100 \mu \mathrm{M})$. Scale bar: $50 \mu \mathrm{m}$. (d) Graphs of superoxide production in mesenteric arteries measured continuously in the presence or absence of BRP2 by using $5 \mu \mathrm{mol} \mathrm{L}^{-1}$ lucigenin-enhanced chemiluminescence. Values are mean \pm s.e.m., expressed as RLU/(s.mg dry weight) $(n=4)$.

on HO-1, NQO1, and SOD enzymatic expression was assessed. We observed that the expression of cytoprotective enzymes was significantly enhanced in the presence of $\mathrm{H}_{2} \mathrm{O}_{2}$ ( $1 \mathrm{mM} ; \quad p<0.001$ vs. control). Administration of BRP2 $(100-1 \mu \mathrm{M})$ further increased HO-1 $(p<0.001$ vs. $\mathrm{H}_{2} \mathrm{O}_{2}$; Figure 4(b)), NQO1 $\left(p<0.001\right.$ vs. $\mathrm{H}_{2} \mathrm{O}_{2}$; Figure $4(\mathrm{c}))$, and SOD expression $\left(p<0.001\right.$ vs. $\mathrm{H}_{2} \mathrm{O}_{2}$; Figure $4(\mathrm{~d})$ ). Nrf2 is generally held in the cytoplasm as an inactive complex bound to a repressor molecule and sensor of intracellular redox state. We found that in a timedependent manner, BRP2 is able to induce Nrf2 translocation to the nucleus, where it turns active. Already starting from 1 hour of treatment, it is possible to appreciate the translocation of this factor that becomes maximal after 6 hours from BRP2 treatment (Figure 5(a)). Moreover, associ- ated with the Nrf2 translocation, it was possible to note that at 1 hour there was an increase in MnSOD expression (Figure 5(b)).

It is well known that Ang II-induced ROS production is mainly mediated by NADPH oxidase activation, a multimeric complex that requires the small GTPase Rac1 to become active. Some studies have reported the functional and mechanistic connection between Racl and the transcription factor Nrf2. Based on these evidences, using the pull-down assay, we found a 50\% reduction of Rac1GTP after 1 hour of BRP2 treatment that further reduces up to six hours, thus supporting the capability of BRP2 to inhibit the angiotensin II-induced ROS production through NADPH oxidase recruitment inhibiting Rac1 activation (Figure 5(c)). 


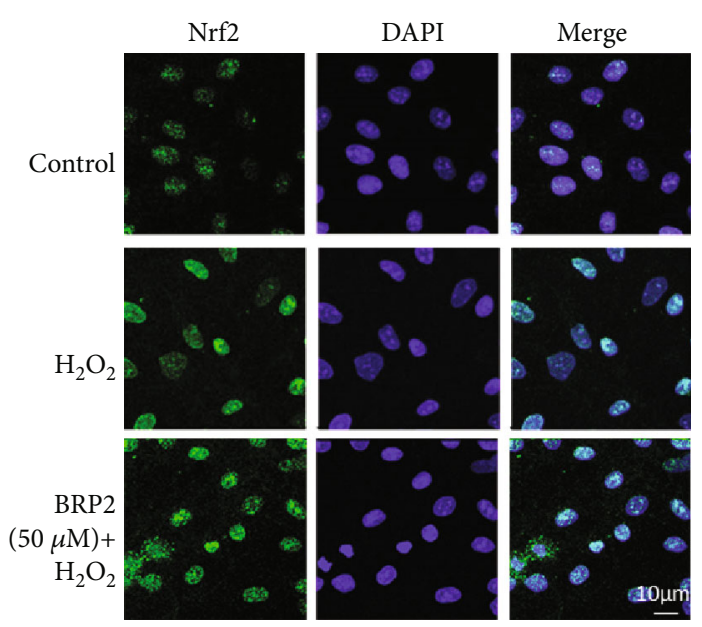

(a)

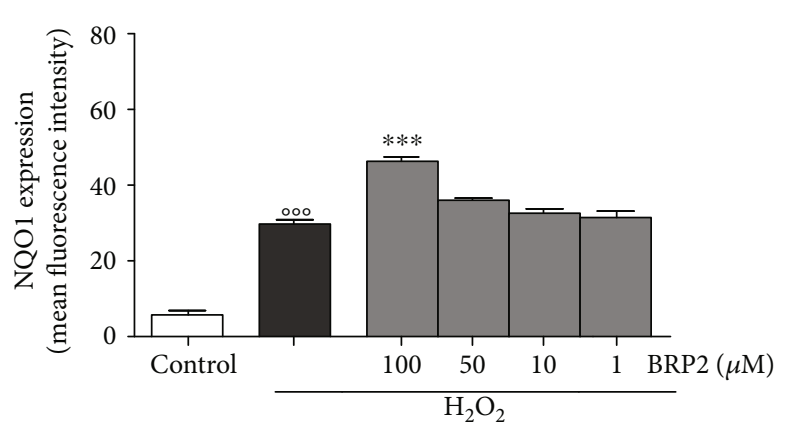

(c)

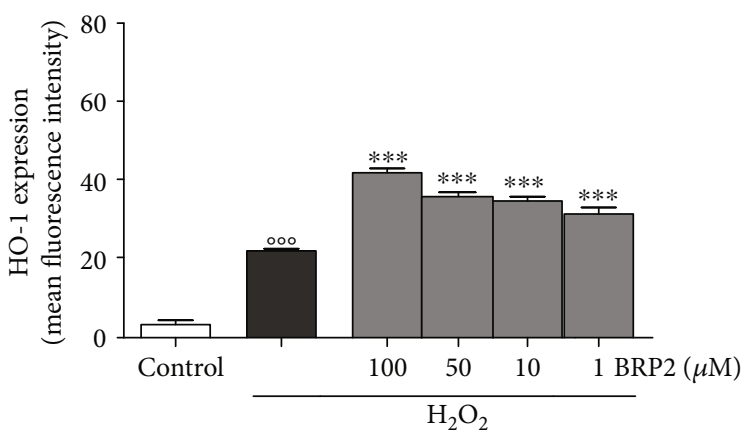

(b)

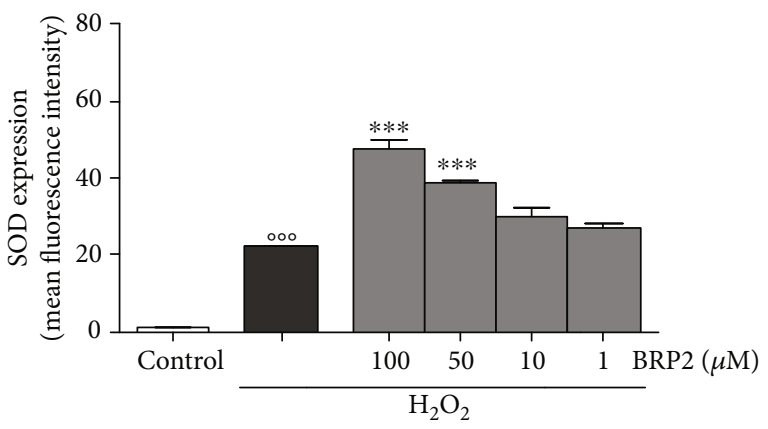

(d)

FiguRE 4: (a) Effect of BRP2 on Nrf2 nuclear translocation (scale bar: $10 \mu \mathrm{m}$ ). Blue fluorescence and green fluorescence indicate localization of the nucleus (DAPI) and Nrf2, respectively. Effect of BRP2 on (b) HO-1, (c) NQO1, and (d) SOD expression in the IEC-6 cells, evaluated by the cytofluorimetric technique. Values, mean \pm s.e.m., are expressed as $\%$ of inhibition of HO- $1, \mathrm{NQO} 1$, and $\mathrm{SOD}$ expression vs. $\mathrm{H}_{2} \mathrm{O}_{2}{ }^{\circ{ }^{\circ 0}}$ denotes $p<0.001$ vs. control. $* * *$ denotes $p<0.001$ vs. $\mathrm{H}_{2} \mathrm{O}_{2}$.

\section{Discussion}

In our previous study, the peptidomic profile of six different commercial dairy products based on buffalo milk was highlighted, revealing the presence of numerous peptides with immunomodulatory, antihypertensive, antioxidant, antimicrobial, anticancer, and antidiabetic properties [17]. However, only one-third of the identified peptides showed a recognized biological activity. Based on this data, we started a rational biological characterization of the six selected commercial products [18]. Buffalo ricotta cheese showed the highest antioxidant activity, compared to the other investigated buffalo dairy products. The peptidomic approach led to the identification of an abundant peptide, corresponding to the fragment $60-72$ of $\beta$-lactoglobulin, namely, BRP, with interesting antioxidant activity [18]. With respect to the previous study, based on ultrafiltration with different cut-off membranes, in the present study, we fractionated the entire buffalo ricotta cheese digest by semipreparative liquid chromatography. Two main fractions were obtained in the most active fraction, and abundant $\beta$-lactoglobulin peptides (f168-174, SFNPTQL, and
BRP2) were detected. The antioxidant potential of this peptide was not reported so far (see Supporting Information Appendix S4); thus, we focused on its possible potential against oxidative stress, in particular on its ability to decrease ROS release. The intestine is the main organ of exposure and/or absorption of nutrients, toxic food contaminants, and metabolic products coming from the intestinal bacteria. The alteration of the integrity and function of the intestinal epithelium produces a negative impact on the rest of the body [35]. In many cases, the intestine responds adequately against the oxidative stress, but aging or disequilibrium in the redox state of the gut can induce intestinal pathologies such as inflammatory bowel disease, gastroduodenal ulcers, and colon cancer [36].

Our results showed that $\beta$-lactoglobulin-derived peptide BRP2 reduced ROS release induced by $\mathrm{H}_{2} \mathrm{O}_{2}$ in IEC- 6 cells. Interestingly, BRP2 possessed a discrete bioavailability, showing a moderate absorption through a fully differentiated Caco-2 intestinal monolayer, without affecting its integrity and tight junction zonulin-1 protein expression.

To understand the antioxidant effect of BRP2 peptide, its molecular basis was investigated. 

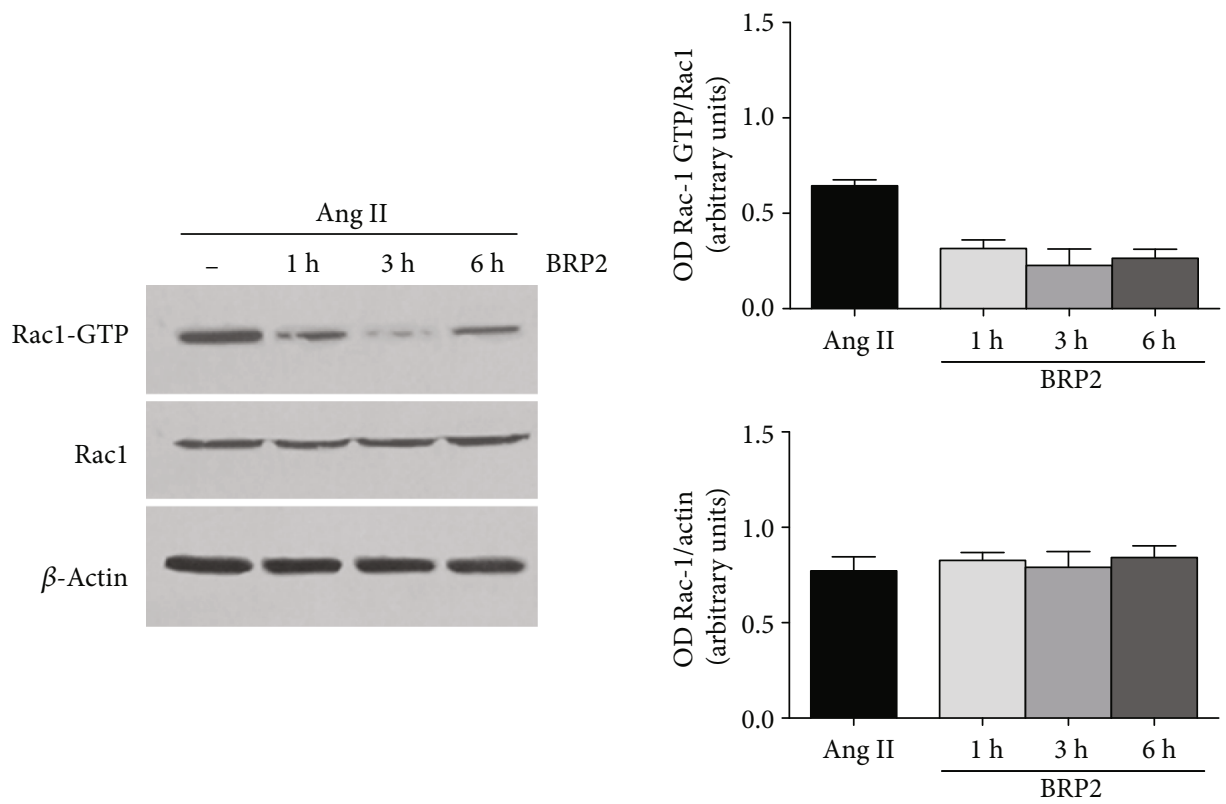

(a)
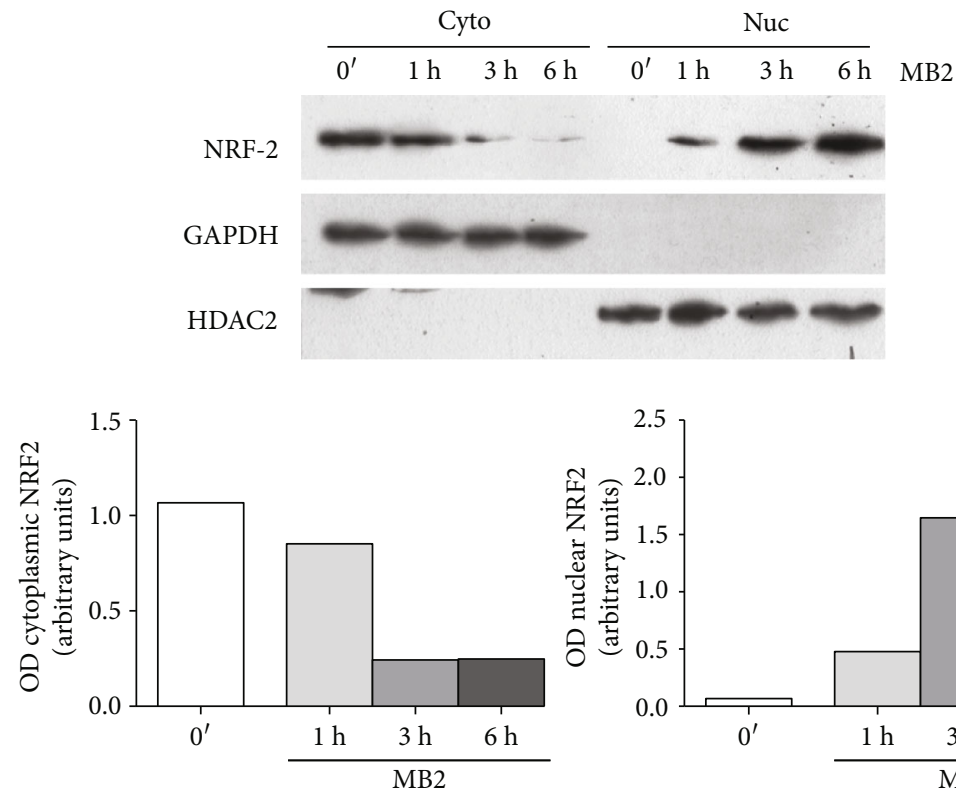

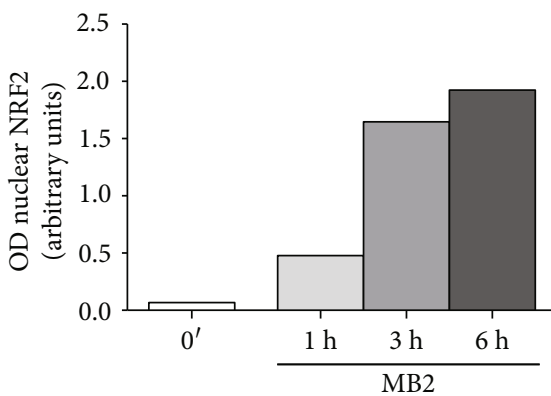

(b)

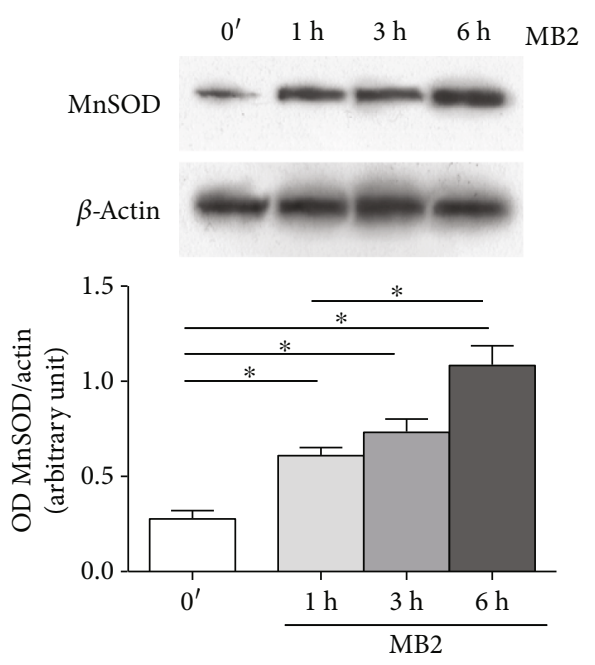

(c)

Figure 5: (a) Representative immunoblot from the pull-down assay of mouse mesenteric arteries for active Rac1 (Rac1-GTP). (b) Immunoblot analysis for Nrf2. Cytoplasmic (Cyto) and nuclear (Nuc) fractions were prepared from untreated mouse mesenteric arteries or treated with BRP2. GAPDH and HDAC2 were used as cytoplasmic and nuclear markers, respectively. Right: nuclear/cytoplasmic ratios for Nrf2 are plotted from densitometry $(n=3)$. (c) Representative immunoblot for MnSOD in mouse mesenteric arteries treated with BRP2 $(100 \mu \mathrm{M})$ and Ang II $\left(10^{-5} \mathrm{M}\right)(n=3)$.

Nrf2 is a transcription factor that plays a central role in the regulation of antioxidant and phase 2 detoxifying enzymes and related proteins [37]. An increase in intracellular ROS enhances nuclear translocation of Nrf2 and expression of its target genes such as HO-1, NQO1, and SOD [38, 39]. Our results indicated that BRP2 protects intestinal epithelial cells from oxidative stress by ROS release inhibition and by upregulation of cytoprotective enzymes via the Nrf2/ARE pathway.
An oxidant mechanism of BRP2 could be related to the presence of amino acidic residues such as proline and threonine in its primary sequence as previously reported for $\beta$-lactoglobulin and $\beta$-casein peptides $[18,40]$.

A growing body of evidence indicates that an imbalance between endogenous reactive oxygen species and antioxidants in favor of the former contributes markedly to vascular dysfunction [41]. Based on the local antioxidant properties and on the moderate intestinal permeation of BRP2, we 
decided to investigate its potential systemic effects in an ex vivo mouse model of vascular reactivity. The most important endogenous bioactive octapeptide that exerts a potent vasoconstrictor through ROS production, modulating systemic hemodynamic parameters, is represented by Ang II. Our studies clearly demonstrated that pretreatment with BRP2 inhibits the Ang II-derived vasoconstrictive responses of mouse mesenteric arteries, in a dose-dependent manner. The $90 \%$ of inhibition after the exposure to the maximal dose of the peptide was obtained. This potent effect evoked by BRP2 is strictly related to its antioxidant properties, counteracting the oxidative stress induced by Ang II. In this regard, several evidences suggest that $\mathrm{NAD}(\mathrm{P}) \mathrm{H}$ oxidase is a major source recruited by Ang II to induce ROS generation in the vascular wall [42]. The evaluation of NADPH oxidase activity revealed a significant reduction of enzymatic activity after pretreatment with BRP2.

NOX is a multisubunit enzyme complex that requires specific interactions with a plethora of molecules. In this regard, the small GTPase Rac1 is essential for the correct assembly of NADPH subunits and their activation [43]. The treatment of mesenteric arteries with BRP2 significantly reduces Racl activation, supporting the effect of the peptide on the reduction of NADPH oxidase activity and the reduction of vasoconstrictive responses to Ang II. These ex vivo results demonstrate that $\mathrm{BRP} 2$ is able to act on two concomitant mechanisms, the reduction of the active form of Racl with a consequent reduction of NOX activity and the induction of nuclear translocation of Nrf2 that is pivotal in cellular defense against oxidative stress [44].

\section{Conclusions}

In conclusion, the results obtained highlight the important role of BRP2 in intestinal and cardiovascular protection, both inhibiting ROS release and enhancing an important antioxidant response consisting of $\mathrm{Nrf} 2$ pathway activation and cytoprotective enzyme expression. The antioxidant effects evoked in mice mesenteric arteries suggest BRP2 as a novel peptide candidate with promising cardiovascular effects and pave the way to its in vivo characterization in a model of cardiovascular disease.

\begin{tabular}{|c|c|}
\hline \multicolumn{2}{|c|}{ Abbreviations } \\
\hline Ang II: & Angiotensin II \\
\hline BR: & Buffalo ricotta \\
\hline BRF: & Buffalo ricotta fraction \\
\hline BRP: & Buffalo ricotta peptide \\
\hline Caco-2: & Colorectal adenocarcinoma \\
\hline DAPI: & $\begin{array}{l}4^{\prime}, 6 \text {-diamidine- } 2^{\prime} \text {-phenylindole } \\
\text { dihydrochloride }\end{array}$ \\
\hline DHE: & Dihydroethidium \\
\hline GI: & Gastrointestinal \\
\hline GAPDH: & Glyceraldehyde 3-phosphate dehydrogenase \\
\hline $\mathrm{H}_{2}$ DCF-DA: & $2^{\prime}, 7^{\prime}$-dichlorofluorescin-diacetate \\
\hline HDAC2: & Histone deacetylase 2 \\
\hline HO-1: & Heme oxygenase-1 \\
\hline IEC-6: & Intestinal epithelial cell line \\
\hline
\end{tabular}

$\begin{array}{ll}\text { NO: } & \text { Nitric oxide } \\ \text { NOX: } & \text { NADPH oxidase } \\ \text { NQO1: } & \text { NAD(P)H quinone oxidoreductase 1 } \\ \text { Nrf2: } & \text { Nuclear factor erythroid 2-related factor 2 } \\ \text { Rac1: } & \text { Ras-related C3 botulinum toxin substrate 1 } \\ \text { ROS: } & \text { Reactive oxygen species } \\ P_{a p p}: & \text { Apparent permeability coefficient } \\ \text { SOD: } & \text { Superoxide dismutase. }\end{array}$

\section{Data Availability}

The data used to support the findings of this study are included within the article and the supplementary information files.

\section{Conflicts of Interest}

The authors declare no conflict of interest.

\section{Acknowledgments}

The authors would like to thank San Salvatore Dairy Factory (Capaccio, SA, Italy) which kindly gifted the buffalo ricotta cheese. This project was supported by the project Progetto PON Ricerca e Innovazione 2014-2020 titolo: "PROGEMA - Processi Green per l'Estrazione di principi attivi e la depurazione di Matrici di scarto e non" (ARS01_00432).

\section{Supplementary Materials}

Figure S1: (A) chromatographic profile acquired by RPUHPLC-UV and (B) mass spectrum of synthetic BRP2 obtained by direct infusion Fourier-transform ion cyclotron resonance MS. Figure S2: transport of BRP2 across Caco-2 cell monolayer. Table S1: the apparent permeability coefficient $\left(P_{\text {app }}\right)$ values of BRP2 with different concentrations. Figure S3: fluorescence micrograph of the Caco-2 cell monolayers. Caco-2 cell monolayers treated with BRP2 $(50 \mu \mathrm{M}$, $2 \mathrm{~h}$ ) from TEER experiments were stained for tight junction protein expression of zonulin-1 (FITC, green). Nuclei were counterstained with DAPI (blue). Pictures are representative of two independent experiments. Original magnification, 200x. Figure S4: (A) graphs of NADPH superoxide production in IEC-6 cells measured continuously in the presence or absence of BRP2 by using $5 \mu \mathrm{mol} \mathrm{L}^{-1}$ lucigenin-enhanced chemiluminescence. Values are mean \pm s.e.m., expressed as counts/mg proteins $(n=4)$. (B) Representative immunoblot of three independent experiments from the pull-down assay of IEC- 6 cells for active Rac1 (Rac1-GTP), Ang II (10-5 M), and BRP2 $(100 \mu \mathrm{M})(n=4)$. (Supplementary Materials)

\section{References}

[1] G. Pierri, D. Kotoni, P. Simone et al., "Analysis of bovine milk caseins on organic monolithic columns: an integrated capillary liquid chromatography-high resolution mass spectrometry approach for the study of time-dependent casein degradation," Journal of Chromatography A, vol. 1313, pp. 259-269, 2013. 
[2] G. C. Tenore, A. Ritieni, P. Campiglia et al., “Antioxidant peptides from "Mozzarella di Bufala Campana DOP" after simulated gastrointestinal digestion: _In vitro_intestinal protection, bioavailability, and anti-haemolytic capacity," Journal of Functional Foods, vol. 15, pp. 365-375, 2015.

[3] E. Sommella, G. Pepe, G. Ventre et al., "Detailed peptide profiling of "Scotta": from a dairy waste to a source of potential health-promoting compounds," Dairy Science \& Technology, vol. 96, no. 5, pp. 763-771, 2016.

[4] T. Sayd, C. Dufour, C. Chambon, C. Buffière, D. Remond, and V. Santé-Lhoutellier, "Combined _in vivo_ and _in silico_ approaches for predicting the release of bioactive peptides from meat digestion," Food Chemistry, vol. 249, pp. 111-118, 2018.

[5] M. Chalamaiah, B. Dinesh kumar, R. Hemalatha, and T. Jyothirmayi, "Fish protein hydrolysates: proximate composition, amino acid composition, antioxidant activities and applications: a review," Food Chemistry, vol. 135, no. 4, pp. 3020-3038, 2012.

[6] A. M. Fiat, D. Migliore-Samour, P. Jollès, L. Drouet, C. Bal dit Sollier, and J. Caen, "Biologically active peptides from milk proteins with emphasis on two examples concerning antithrombotic and immunomodulating activities," Journal of Dairy Science, vol. 76, no. 1, pp. 301-310, 1993.

[7] S. Sakanaka, Y. Tachibana, N. Ishihara, and L. Raj Juneja, "Antioxidant activity of egg-yolk protein hydrolysates in a linoleic acid oxidation system," Food Chemistry, vol. 86, no. 1, pp. 99-103, 2004.

[8] F. Sansone, T. Mencherini, P. Picerno et al., "Microencapsulation by spray drying of Lannea microcarpa extract: Technological characteristics and antioxidant activity," Journal of Pharmacy \& Pharmacognosy Research, vol. 2, no. 4, pp. 100109, 2014.

[9] A. Sofo, B. Lundegårdh, A. Mårtensson et al., "Different agronomic and fertilization systems affect polyphenolic profile, antioxidant capacity and mineral composition of lettuce," Scientia Horticulturae, vol. 204, pp. 106-115, 2016.

[10] S. Adesso, G. Pepe, E. Sommella et al., "Anti-inflammatory and antioxidant activity of polyphenolic extracts from Lactuca sativa (var. Maravilla de Verano) under different farming methods," Journal of the Science of Food and Agriculture, vol. 96, no. 12, pp. 4194-4206, 2016.

[11] W. Dröge, "Free radicals in the physiological control of cell function," Physiological Reviews, vol. 82, no. 1, pp. 47-95, 2002.

[12] Y. H. Wei, C. Y. Lu, C. Y. Wei, Y. S. Ma, and H. C. Lee, "Oxidative stress in human aging and mitochondrial diseaseconsequences of defective mitochondrial respiration and impaired antioxidant enzyme system," The Chinese Journal of Physiology, vol. 44, no. 1, pp. 1-11, 2001.

[13] Y. J. Kim, E. H. Kim, and K. B. Hahm, "Oxidative stress in inflammation-based gastrointestinal tract diseases: challenges and opportunities," Journal of Gastroenterology and Hepatology, vol. 27, no. 6, pp. 1004-1010, 2012.

[14] T. Heitzer, T. Schlinzig, K. Krohn, T. Meinertz, and T. Münzel, "Endothelial dysfunction, oxidative stress, and risk of cardiovascular events in patients with coronary artery disease," Circulation, vol. 104, no. 22, pp. 26732678, 2001.

[15] R. M. Touyz, "Reactive oxygen species, vascular oxidative stress, and redox signaling in hypertension: what is the clinical significance?," Hypertension, vol. 44, no. 3, pp. 248-252, 2004.
[16] E. H. Tang and P. M. Vanhoutte, "Endothelial dysfunction: a strategic target in the treatment of hypertension?," Pflügers Archiv - European Journal of Physiology, vol. 459, no. 6, pp. 995-1004, 2010.

[17] M. G. Basilicata, G. Pepe, E. Sommella et al., "Peptidome profiles and bioactivity elucidation of buffalo-milk dairy products after gastrointestinal digestion," Food Research International, vol. 105, pp. 1003-1010, 2018.

[18] M. Basilicata, G. Pepe, S. Adesso et al., “Antioxidant properties of buffalo-milk dairy products: a $\beta$-Lg peptide released after gastrointestinal digestion of buffalo ricotta cheese reduces oxidative stress in intestinal epithelial cells," International Journal of Molecular Sciences, vol. 19, no. 7, p. 1955, 2018.

[19] T. Tavares, M.-Á. Sevilla, M.-J. Montero, R. Carrón, and F. X. Malcata, "Acute effect of whey peptides upon blood pressure of hypertensive rats, and relationship with their angiotensin-converting enzyme inhibitory activity," Molecular Nutrition \& Food Research, vol. 56, no. 2, pp. 316-324, 2012.

[20] K. D. Ballard, R. S. Bruno, R. L. Seip et al., "Acute ingestion of a novel whey-derived peptide improves vascular endothelial responses in healthy individuals: a randomized, placebo controlled trial," Nutrition Journal, vol. 8, no. 1, 2009.

[21] H. Ijäs, M. Collin, P. Finckenberg et al., "Antihypertensive opioid-like milk peptide $\alpha$-lactorphin: lack of effect on behavioural tests in mice," International Dairy Journal, vol. 14, no. 3, pp. 201-205, 2004

[22] W. Maes, J. van Camp, V. Vermeirssen et al., "Influence of the lactokinin Ala-Leu-Pro-Met-His-Ile-Arg (ALPMHIR) on the release of endothelin-1 by endothelial cells," Regulatory Peptides, vol. 118, no. 1-2, pp. 105-109, 2004.

[23] G. Pepe, F. Pagano, S. Adesso et al., "Bioavailable Citrus sinensis extract: polyphenolic composition and biological activity," Molecules, vol. 22, no. 4, p. 623, 2017.

[24] G. Bianco, B. Fontanella, L. Severino, A. Quaroni, G. Autore, and S. Marzocco, "Nivalenol and deoxynivalenol affect rat intestinal epithelial cells: a concentration related study," PLoS One, vol. 7, no. 12, p. e52051, 2012.

[25] S. Marzocco, S. Adesso, M. Alilou, H. Stuppner, and S. Schwaiger, "Anti-inflammatory and anti-oxidant potential of the root extract and constituents of Doronicum austriacum," Molecules, vol. 22, no. 6, p. 1003, 2017.

[26] S. Marzocco, L. Calabrone, S. Adesso et al., "Anti-inflammatory activity of horseradish (Armoracia rusticana) root extracts in LPS-stimulated macrophages," Food \& Function, vol. 6, no. 12, pp. 3778-3788, 2015.

[27] I. Hubatsch, E. G. Ragnarsson, and P. Artursson, "Determination of drug permeability and prediction of drug absorption in Caco-2 monolayers," Nature Protocols, vol. 2, no. 9, pp. 21112119, 2007.

[28] S. Tavelin, J. Grasjo, J. Taipalensuu, G. Ocklind, and P. Artursson, Methods in Molecular Biology, C. Wise, Ed., vol. 188, Humana Press, Totowa, New Jersey, 2002.

[29] R. Ranieri, E. Ciaglia, G. Amodio et al., "N6-isopentenyladenosine dual targeting of AMPK and Rab7 prenylation inhibits melanoma growth through the impairment of autophagic flux," Cell Death and Differentiation, vol. 25, no. 2, pp. 353367, 2018.

[30] A. Carrizzo, M. Ambrosio, A. Damato et al., "Morus alba extract modulates blood pressure homeostasis through eNOS signaling," Molecular Nutrition \& Food Research, vol. 60, no. 10, pp. 2304-2311, 2016. 
[31] A. Carrizzo, C. Vecchione, A. Damato et al., "Rac1 pharmacological inhibition rescues human endothelial dysfunction," Journal of the American Heart Association, vol. 6, no. 3, 2017.

[32] A. Carrizzo, A. Puca, A. Damato et al., "Resveratrol improves vascular function in patients with hypertension and dyslipidemia by modulating NO metabolism," Hypertension, vol. 62, no. 2, pp. 359-366, 2013.

[33] C. O. Chan, J. Jing, W. Xiao et al., "Enhanced intestinal permeability of bufalin by a novel bufalin-peptidedendrimer inclusion through Caco-2 cell monolayer," Molecules, vol. 22, no. 12, p. 2088, 2017.

[34] Q. Ma, "Role of nrf2 in oxidative stress and toxicity," Annual Review of Pharmacology and Toxicology, vol. 53, pp. 401426, 2013.

[35] A. S. Londero, M. R. Arana, V. G. Perdomo et al., "Intestinal multidrug resistance-associated protein 2 is down-regulated in fructose-fed rats," The Journal of Nutritional Biochemistry, vol. 40, pp. 178-186, 2017.

[36] I. Moret, E. Cerrillo, A. Navarro-Puche et al., "Oxidative stress in Crohn's disease," Gastroenterología y Hepatología, vol. 37, no. 1, pp. 28-34, 2014.

[37] H. Zhu, K. Itoh, M. Yamamoto, J. L. Zweier, and Y. Li, "Role of Nrf2 signaling in regulation of antioxidants and phase 2 enzymes in cardiac fibroblasts: protection against reactive oxygen and nitrogen species-induced cell injury," FEBS Letters, vol. 579, no. 14, pp. 3029-3036, 2005.

[38] V. Afonso, R. Champy, D. Mitrovic, P. Collin, and A. Lomri, "Reactive oxygen species and superoxide dismutases: role in joint diseases," Joint, Bone, Spine, vol. 74, no. 4, pp. 324-329, 2007.

[39] Y. Wang, R. Branicky, A. Noë, and S. Hekimi, "Superoxide dismutases: dual roles in controlling ROS damage and regulating ROS signaling," The Journal of Cell Biology, vol. 217, no. 6, pp. 1915-1928, 2018.

[40] G. Pepe, E. Sommella, G. Ventre et al., “Antioxidant peptides released from gastrointestinal digestion of "Stracchino" soft cheese: Characterization, in vitro intestinal protection and bioavailability," Journal of Functional Foods, vol. 26, pp. 494-505, 2016.

[41] U. Förstermann, "Oxidative stress in vascular disease: causes, defense mechanisms and potential therapies," Nature Clinical Practice. Cardiovascular Medicine, vol. 5, no. 6, pp. 338-349, 2008.

[42] D. Sorescu and K. K. Griendling, "Reactive oxygen species, mitochondria, and $\mathrm{NAD}(\mathrm{P}) \mathrm{H}$ oxidases in the development and progression of heart failure," Congestive Heart Failure, vol. 8, no. 3, pp. 132-140, 2002.

[43] A. Carrizzo, M. Forte, M. Lembo, L. Formisano, A. A. Puca, and C. Vecchione, "Rac-1 as a new therapeutic target in cerebro- and cardio-vascular diseases," Current Drug Targets, vol. 15, no. 13, pp. 1231-1246, 2014.

[44] T. Ashino, M. Yamamoto, T. Yoshida, and S. Numazawa, "Redox-sensitive transcription factor Nrf2 regulates vascular smooth muscle cell migration and neointimal hyperplasia," Arteriosclerosis, Thrombosis, and Vascular Biology, vol. 33, no. 4, pp. 760-768, 2013. 


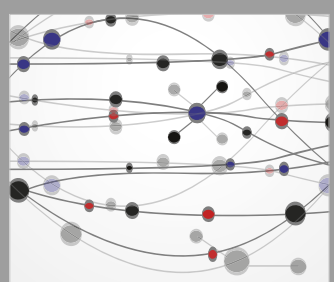

The Scientific World Journal
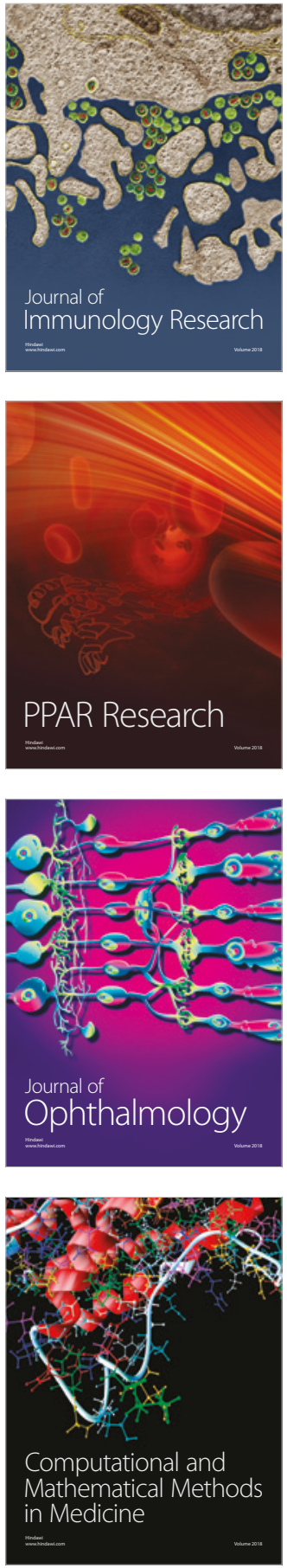

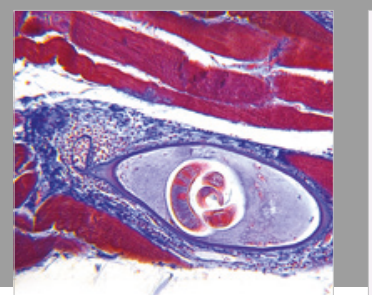

Gastroenterology Research and Practice

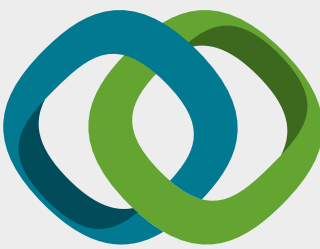

\section{Hindawi}

Submit your manuscripts at

www.hindawi.com
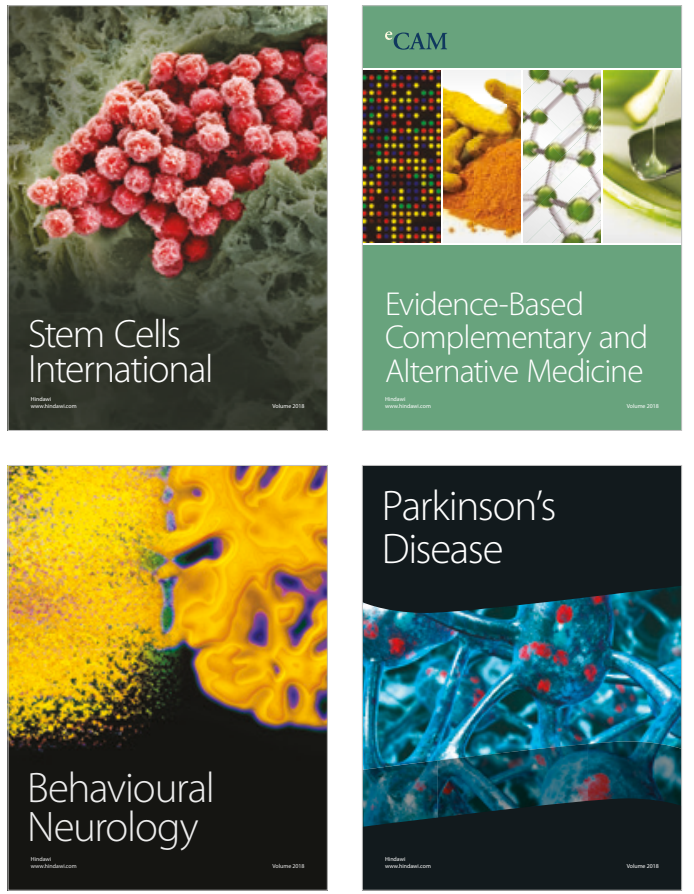

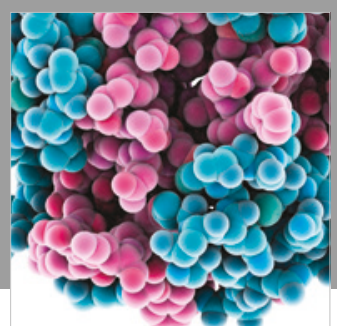

ournal of

Diabetes Research

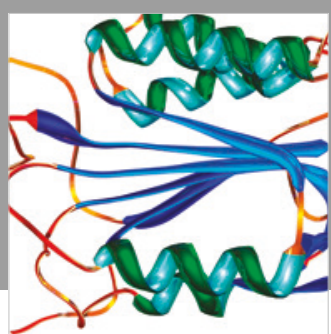

Disease Markers
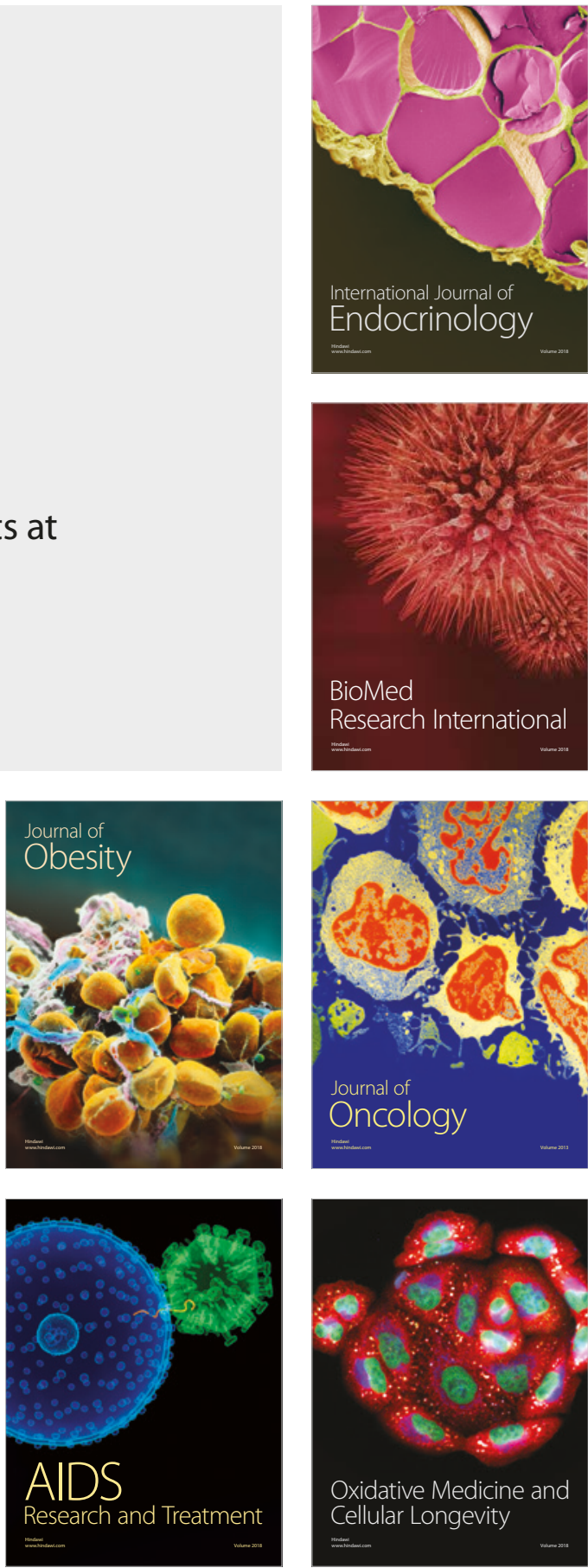